\title{
Estudo de Caso: EAD Através da TV Digital Interativa com o Software Trânsito Legal
}

\author{
Flávio Ricardo Dias ${ }^{1}$, Ariádnes Rodrigues ${ }^{2}$, Ivaldir H. de Farias Junior ${ }^{1}$ \\ ${ }^{1}$ Universidade Federal de Pernambuco (UFPE) - Recife - PE - Brasil \\ ${ }^{2}$ Universidade do Estado de Pernambuco (UPE) - Caruaru - PE - Brasil
}

flavioricardodias@hotmail.com, ariadnesrodrigues@gmail.com, ivaldirjr@gmail.com

\section{Resumo}

O sistema de difusão de sinais de televisão no Brasil está em pleno processo de transição, e no decorrer dessa transformação, as tecnologias analógica e digital estarão sendo transmitidas em paralelo. Dois dos principais objetivos da implantação da TV Digital no país são as possibilidades de inclusão social para milhões de brasileiros por meio do acesso à tecnologia digital, uma vez que a televisão está presente em mais de $90 \%$ dos lares, e a universalização da educação à distância pela disponibilização de aplicativos de T-Learning, que propiciarão educação a uma grande parte da população. Este artigo teve como metodologia de pesquisa uma revisão bibliográfica apoiada por uma pesquisa qualitativa e quantitativa, além de uma prototipação da aplicação, usando como principal ferramenta de coleta a aplicação de questionários. A proposta deste estudo é comprovar a viabilidade da realização do ensino à distância pela TV Digital através de aplicações com interatividade local.

Palavras-chave: TV Digital, TV Digital Interativa, Educação à Distância, T-Learning, Interatividade.

\begin{abstract}
The system of broadcasting television signals in Brazil is in the process of transition, and during such processing analog and digital technologies are being transmitted in parallel. Two major goals of the deployment of Digital TV in the country are the possibility of social inclusion for millions of Brazilians by access to digital technology since the television is present in more than 90\% households, and the universalization of distance education by availability of applications for T-Learning, which will provide education to a large population. This article was a review of research methodology literature supported by a qualitative and quantitative research, and a prototyping of application, study using as the primary tool for collecting questionnaires. The purpose of this study is to demonstrate the feasibility of implementation of distance learning for Digital TV applications with interactivity through the site.
\end{abstract}

Keywords: Digital TV, Interactive Digital TV, Distance learning, T-Learning, Interactivity. 


\section{INTRODUÇÃO}

No Brasil, a televisão é considerada um meio de comunicação com forte poder formativo pois está presente em quase todos os lares. É através dela que milhões de brasileiros adquirem conhecimento, informação, cultura e, principalmente entretenimento.

A digitalização da televisão traz consigo possibilidades que atualmente não seriam possíveis de serem realizadas pelas limitações tecnológicas da televisão analógica. Uma das caracterísicas da digitalização que mais incentiva os países desenvolverem alternativas para implantá-la é a possibilidade da "convergência" entre vários meios de comunicação e a interatividade, a partir de um único equipamento (SANTOS, 2006).

Mas no Brasil, a adesão à TV Digital (TVD) tem um embasamento social, ou seja, vai muito mais além do que apenas oferecer à população a possibilidade de receber em suas casas imagens de alta definição ou de escutar sons com altíssima qualidade. O Decreto Presidencial $\mathrm{N}^{\circ}$ 4.901, de 26 de novembro de 2003, que instituiu o Sistema Brasileiro de Televisão Digital (SBTVD), logo em seus primeiros objetivos, destaca as ações de: "I - promover a inclusão social, a diversidade cultural do País e a língua pátria por meio do acesso à tecnologia digital, visando à democratização da informação; e II - propiciar a criação de rede universal de educação à distância”.

Uma vez que a presença do sinal digital é realidade em diversas cidades brasileiras, os desafios a serem superados imediatamente são, por exemplo: a produção de aplicações e serviços interativos de qualidade e a formação de mão-de-obra especializada para os diversos fins que exige essa nova tecnologia.

O desafio dos serviços interativos e de qualidade refere-se a preocupação na mudança de atitude do telespectador diante do conteúdo televisivo. Atualmente o usuário se apresenta puramente passivo ao conteúdo que lhe é apresentado e com a transmissão digital que acompanha serviços inovadores, ele passará a interagir com um ambiente televisivo que o provocará a participar proativa e efetivamente por intermédio de seu próprio aparelho de TV. As aplicações diposnibilizadas para a TVD devem ser suficientemente atrativas, para motivar o telespectador no seu uso e aquisição da cultura da própria interação com a TV, e devem ainda permitir ao usuário, o acesso a essas aplicações de forma fácil e eficiente.

Importantes iniciativas voltadas para TV analógica devem ganhar um tratamento especial quando realizadas no ambiente digitalizado. Programas de Ensino e Educação a Distância (EAD) se tornaram consagradamente reconhecidos, como: TV Cultura, Telecurso 2000, Canal Futura e Salto para o Futuro porém a interação, quando existia, se realizava por meios (telefone, correios, fax, internet) que careciam de agilidade e atratividade. As potencialidades advindas das diversas infra-estruturas envolvidas na formatação da TV Digital Interativa (TVDi) colaboram com a implementação da nova mídia e a população poderá usufruir dos muitos benefícios proporcionados por ela (MONTEIRO, 2009).

Com o processo de migração das tecnologias analógica para a digital iniciado, o presente estudo pretende mostrar a viabilidade de realizar educação a distância por meio do uso de aplicações interativas locais através da TVD, mesmo sem ter atualmente uma definição de qual será o modelo de interatividade plena adotado. O objetivo é, finalmente, motivar prontamente o desenvolvimento e disponibilização de vários tipos de aplicações educativas, que possam vir a ser importante instrumento para proporcionar um sistema educacional mais igualitário e menos restritivo. 
Este estudo tem como hipótese a viabilidade de educação a distância por meio de aplicações com interatividade local através da TV Digital e reflete sob a seguinte problemática: como realizar um ambiente de Ensino e Educação a Distância (EAD) satisfatório para a TVDi que seja atrativo e contemple atributos de usabilidade, em face da indefinição do canal de interatividade?

\section{A TV Digital Interativa}

Assim como qualquer outro meio de comunicação, a TV também é afetada pelo constante processo evolutivo e adaptativo que busca atender as necessidades humanas. Desde 1936, quando o primeiro canal de TV foi lançado pela British Broadcasting Corporation (BBC) de Londres, muito se tem avançado com este tipo de mídia. Na década de 50, surgem as cores, melhorando significativamente a apresentação, depois o aumento do número de canais, e com ele o advento do revolucionário controle remoto, permitindo ao telespectador o poder de escolha, conferindo comodidade e eliminando a necessidade de locomoção para execução das operações básicas com a TV (MONTEZ; BECKER, 2005).

No Brasil, uma das maiores revoluções que a TV tem sofrido é a migração do sistema de transmissão do analógico para o digital. Essas discussões foram iniciadas em meados da década de 90, precisamente em 1998, durante um convênio formado entre o Centro de Pesquisa e Desenvolvimento em Telecomunicações (CPqD) e instituições como Universidade Presbiteriana Mackenzie, a Associação Brasileira de Emissoras de Rádio e Televisão (ABERT) e a Sociedade de Engenharia de Televisão (SET) com a finalidade de conhecer os diversos sistemas de televisão digital existentes. Logo em 1999, uniram-se o CPqD e a Agência Nacional de Telecomunicações (ANATEL) para avaliar, de forma técnica e econômica, qual o padrão de televisão digital que seria utilizado pelo Brasil.

A criação do Sistema Brasileiro de TV Digital (SBTVD) foi realizada em novembro de 2003 e esse fato marcou oficialmente o início da transição do modelo analógico de TV para o modelo digital. O SBTVD, além do objetivo principal, que é a própria transição, possui a inclusão digital como outro importante alvo. Pois com a transição dessas tecnologias será possível a conexão de aparelhos de televisão analógicos à Internet através da utilização de um STB (MONTEZ; BECKER, 2005).

Em 2006 foi formalmente instaurado o Fórum SBTVD (Fórum do Sistema Brasileiro de TV Digital Terrestre) através do decreto presidencial 5.820. O Fórum SBTVD é uma entidade sem fins lucrativos, responsável pelo apoio sobre as políticas e assuntos técnicos que se referem à aprovação de inovações tecnológicas, especificações, desenvolvimento e implantação do SBTVD, bem como, pelo estímulo à criação e melhoria da transmissão e recepção de imagens e sons digitais no país. O Fórum é composto pelas Emissoras de Radiodifusão, Indústrias de Software, Fabricantes de Equipamentos de Recepção ou Transmissão; e pelas Entidades de Ensino e Pesquisa que Desenvolvam Atividades Diretamente Relacionadas ao Sistema Brasileiro de TV Digital (FÓRUM SBTVD, 2008).

No dia 2 de dezembro de 2007 foi feita a primeira transmissão digital na cidade de São Paulo. Em meados de 2016 pretende-se que a migração para a TVD seja finalizada, e até isso acontecer as emissoras estarão transmitindo sua programação em simultcasting. Isso possibilita que os usuários que ainda não adquiriram o conversor ou também conhecido como Set-Top-Box (STB), ou usuários residentes em regiões onde o sinal digital não foi liberado, continuem recebendo normalmente em seus aparelhos a programação disponibilizada pelas emissoras. 
A televisão digital brasileira foi concebida para ser a mais convergente do mundo e possibilitará tecnicamente: "transmissão digital em alta definição (HDTV) e em definição padrão (SDTV); transmissão digital simultânea para recepção fixa, móvel e portátil; e interatividade” (BRASIL, CASA CIVIL, 2006). Isso implica que será necessária a produção de conteúdo relevante para quem adquirir aparelhos, repletos de recursos e de alta definição (TEIXEIRA, 2008).

\subsection{Modalidade do Ensino e Educação a Distância}

A Educação a Distância (EAD) é uma modalidade de ensino/aprendizagem onde se encontra diversas denominações e conceptualizações relacionadas. Frequentemente associase, de forma equivocada, Educação a Distância e Ensino a Distância como processos unívocos. Entretanto, Ensino representa compartilhamento da informação, aprendizagem, instrução, etc., enquanto que Educação, segundo Maroto (1995), é a estratégia básica de formação humana, aprender a aprender, saber pensar, criar, inovar, construir conhecimento, participar, etc.

Para Moran (1994), a EAD é o processo de ensino-aprendizagem, onde professores e alunos estão separados espacial e/ou temporalmente, mas podem estar conectados, interligados por tecnologias, principalmente as telemáticas, como a Internet. Mas também podem ser utilizados o correio, o rádio, a televisão, o vídeo, o CD-ROM, o telefone, o fax, entre outras tecnologias semelhantes. Já para Garcia (1995), a EAD distingue-se da modalidade de ensino presencial por ser um sistema tecnológico de comunicação bidirecional que pode ser massivo e que substitui a interação pessoal na sala de aula entre professor e aluno como meio preferencial de ensino pela ação sistemática e conjunta de diversos recursos didáticos e o apoio de uma organização e tutoria que propiciam uma aprendizagem independente e flexível.

A EAD surgiu da necessidade do desenvolvimento profissional e cultural de milhões de pesssoas. Motivadas por situações como: residência em locais distantes dos núcleos de ensino; reprovação nos cursos regulares; inserção no mercado de trabalho; facilidade para planejar seus programas de estudo e avaliar o progresso realizado; e até mesmo preferência em estudar sozinho, do que em classes numerosas, estas pessoas não podiam frequentar um estabelecimento de ensino presencial, e evoluiu com as tecnologias disponíveis em cada momento histórico, as quais influenciam o ambiente educativo e a sociedade.

Diante deste contexto, podemos perceber que são incessantes os estudos e as pesquisas realizadas para avaliarem tudo o que se apresente aparentemente inviável no ambiente do modelo de ensino e educação a distância. Questões que ganham destaque independente da maneira do modelo EAD (Correspondência, Rádio, Internet, TV Analógica ou Digital) são métodos pedagógicos adotados e suporte tecnológico necessários.

\subsection{EAD na TV digital interativa}

Segundo Bates (2003), T-Learning é o tipo de educação à distância baseado em televisão interativa, ou seja, representa a especificação da TV Digital como a tecnologia que apóia o processo de aprendizado eletrônico denominado E-Learning. Jokipelto (2005) visualiza o T-Learning como uma convergência entre alguns elementos a mais que os colocados por Bates: televisão digital, computador, E-Learning e rede (Figura 1). 


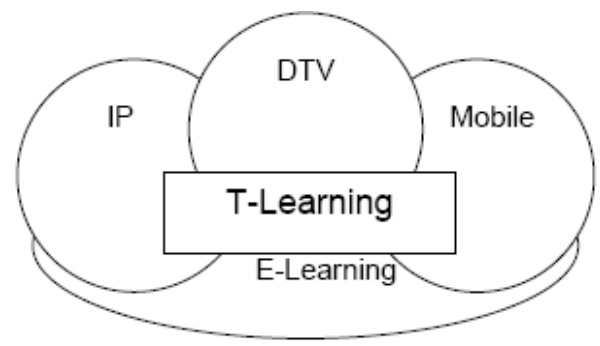

Figura 1. Convergência de tecnologias no T-Learning - Fonte - Jokipelto (2005, p. 1)

Ainda em Bates (2003), o T-Learning possibilitará aos telespectadores o acesso a diversos materiais didáticos, tais como: filmes, imagens, hipertexto, etc., a partir de suas próprias casas, escolas, local de trabalho ou centros comunitários.

\subsection{Trabalhos relacionados: Aplicações EAD para a TVDi}

Algumas aplicações T-Learning, que usaram o modelo de interatividade local, se tornaram projetos bem difundidos no Brasil. Os exemplos seguintes são alguns desses projetos, eles constituem aplicações desenvolvidas para TVDi porém não exclusivamente para a TV aberta conforme as figuras 1 e 2 .

\section{Projeto: Amazonas Interativo}

Objetivo Geral: consiste em um programa para atender a região Amazônica com foco na formação de jovens e adultos, através da tecnologia de TV digital interativa via satélite.

Projetista: Instituto Genius;

Serviços envolvidos: alfabetização digital, educação à distância, comunicação cidadã e gestão escolar (WAISMAN, 2005).
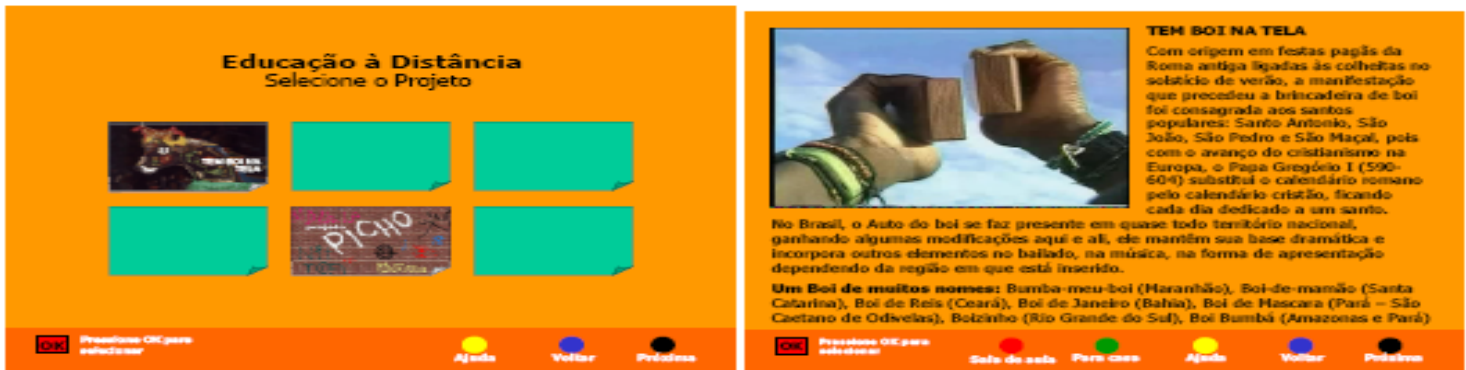

Figura 2. Aplicação Amazonas Interativo

\section{Projeto: A Turma da Árvore}

Objetivo Geral: concebido para crianças não alfabetizadas de até 6 anos e na versão interativa contém vários recursos que proporcionam ao telespectador, interação com o conteúdo.

Serviços envolvidos: O enredo trata de uma turma de amigos que se encontram em cima de uma árvore em uma casa de madeira. A posição da casa permite a eles verem sob outro aspecto a cidade e esse novo jeito de ver o ambiente vai despertando para os temas: educação ambiental, lixo reciclável, saúde e cidadania (TAVARES e SAIBEL, 2006). 

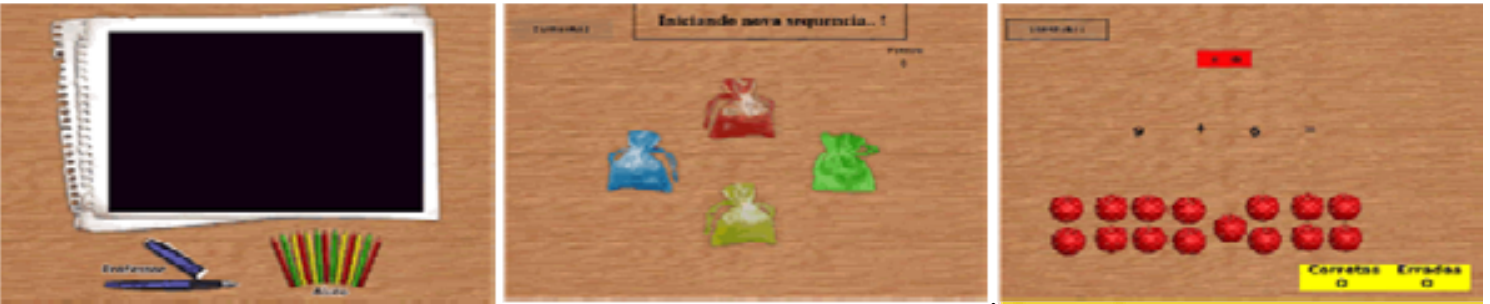

Figura 3. Aplicação A Turma da Árvore

\section{O TRÂNSITO LEGAL}

O objetivo geral deste projeto é a educação no Trânsito, que integram o tema direção defensiva e noções de Sinalização. Todo seu conteúdo foi baseado no CTB - Código de Trânsito Brasileiro (BRASIL. DENATRAN, 2009). É considerado também como um rico material de apoio para quem deseja se reciclar ou vai se submeter aos exames para obtenção da primeira habilitação ou renovação (Figura 4).

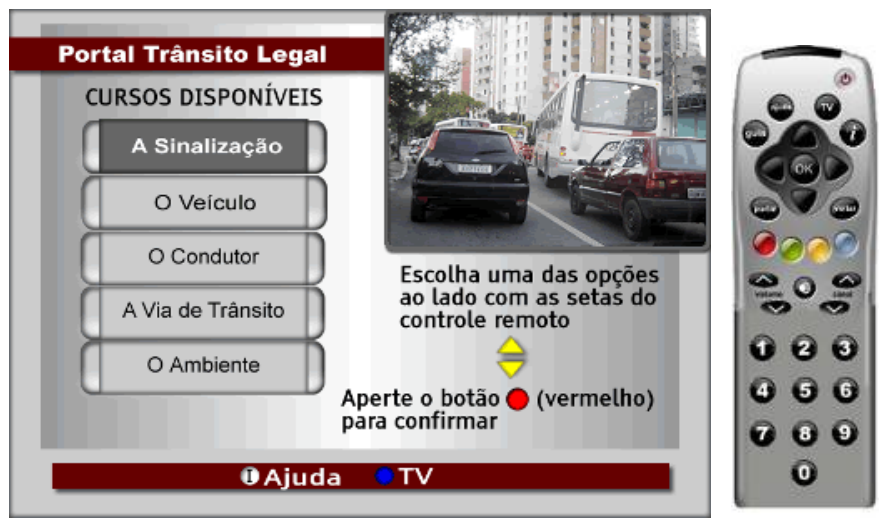

Figura 4. Aplicação Trânsito Legal e controle remoto

O projeto possui uma divisão estruturada sob três pontos de interação (Figura 5): o primeiro é composto pela leitura da teoria sobre o trânsito; o segundo ponto contempla testes com questões objetivas sobre a teoria disponibilizada; por fim, o terceiro ponto é uma área destinada ao entretenimento que contém uma lista de jogos que envolvem a temática da aplicação.
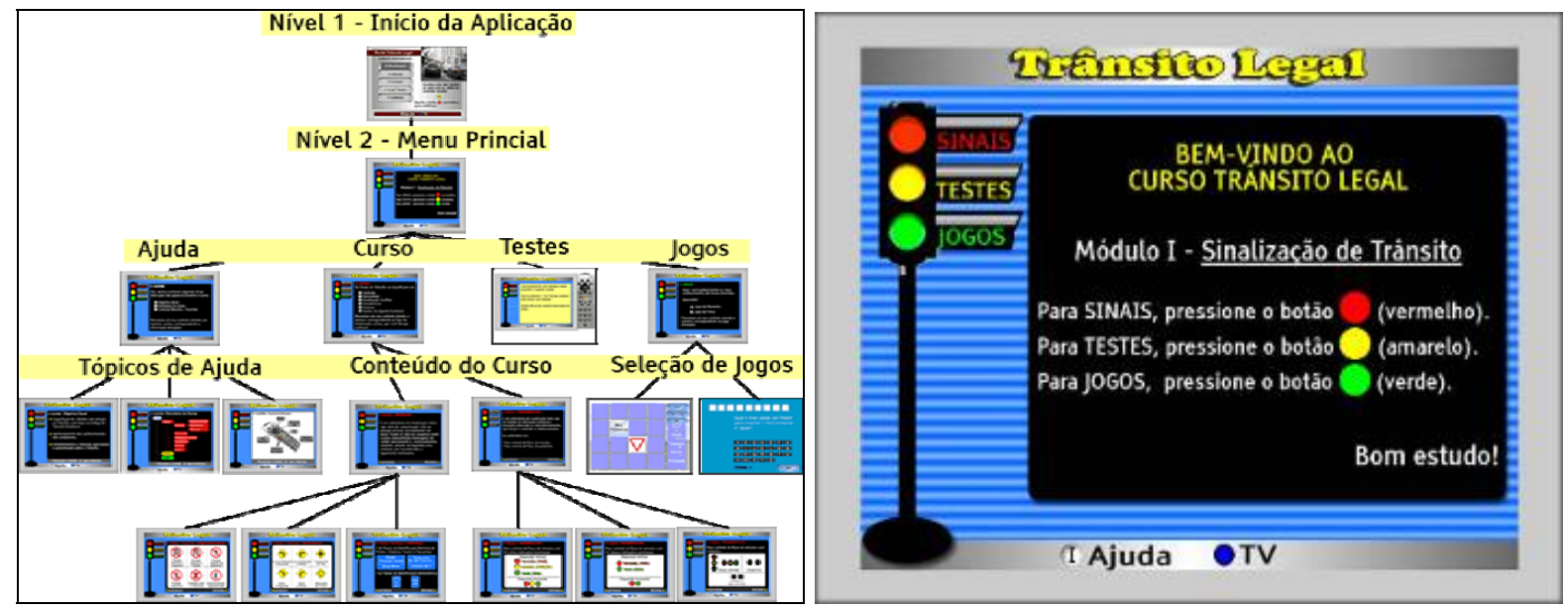

Figura 5. Mapa de navegação das telas e Menu principal 
A interatividade oferecida pelo aplicativo é exclusivamente local, pela ausência de canal de retorno para o provedor do sinal. A proposta do aplicativo é genérica e não esteve voltado especificamente para um determinado tipo de middleware, seja ele GINGA, MHP, DASE ou ARIBA. Pelo motivo da aplicação fornecer apenas uma visão conceitual, o mesmo foi desenvolvido com a ferramenta ADOBE Flash (ADOBE, 2009), mas é totalmente aceitável reescrevê-lo em qualquer outra linguagem de programação. O diagrama de casos de uso (Figura 6) demonstra o funcionamento básico da aplicação:

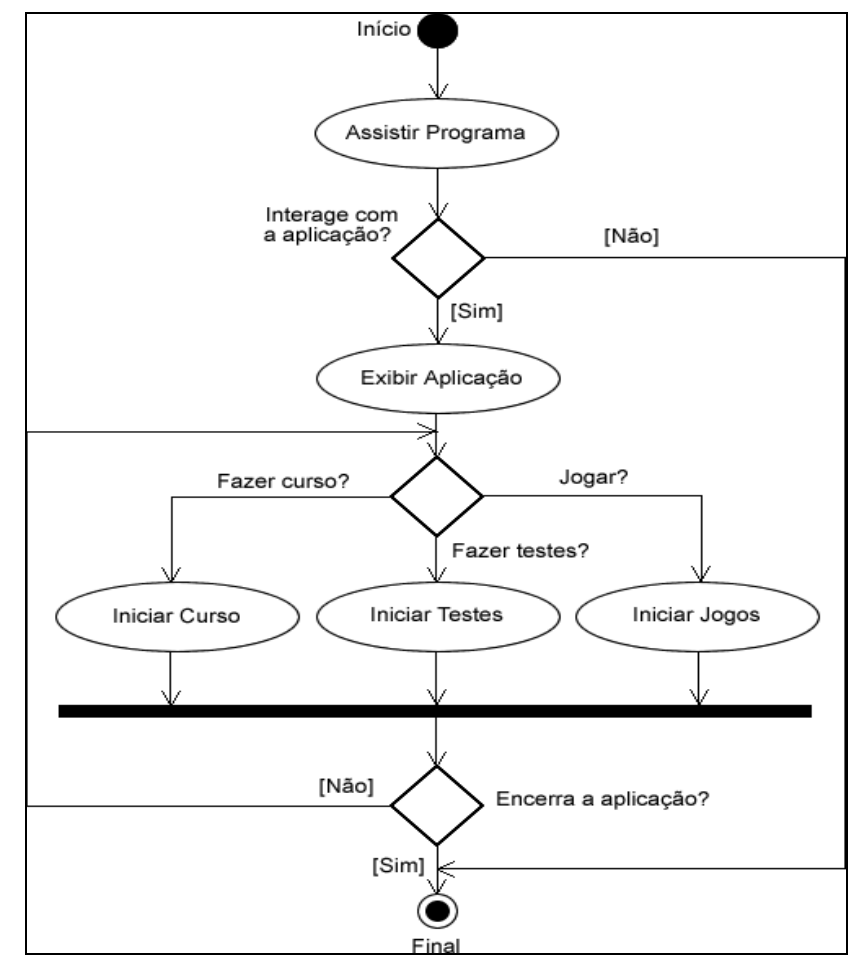

Figura 6. Diagrama de Atividades UML que representa o fluxo interativo da aplicação

Prototipação: A utilização de programas simuladores para a criação de aplicações interativas para a TV digital tem sido bastante explorada em instituições de ensino/pesquisa ou por empresas especializadas no desenvolvimento de software. O objetivo desse tipo de recurso é o experimento e demonstração das funcionalidades contidas nas aplicações, antes que as mesmas possam efetivamente ser colocadas em produção. Essa prática ocorre em função da dificuldade e alto custo na preparação de um ambiente com características próximas a de uma emissora de TV para a realização dos testes.

Em certo momento do estudo, foi realizada uma visita ao laboratório de TV Digital do C.E.S.A.R. (CESAR, 2009) para conhecer em detalhes as características técnicas de algumas aplicações: simuladores, linguagens, códigos fonte, desempenho, tamanho, etc (Figura 7). No que se refere ao aspecto tamanho da aplicação, nenhum dos aplicativos investigados tem mais que 700 Kbytes (gráficos + animações + texto). A maioria dos set-top box comercializados atualmente tem memória superior a 16 Mbytes, que é uma capacidade ainda muito pequena, porém permite a execução de vários tipos de aplicação. 

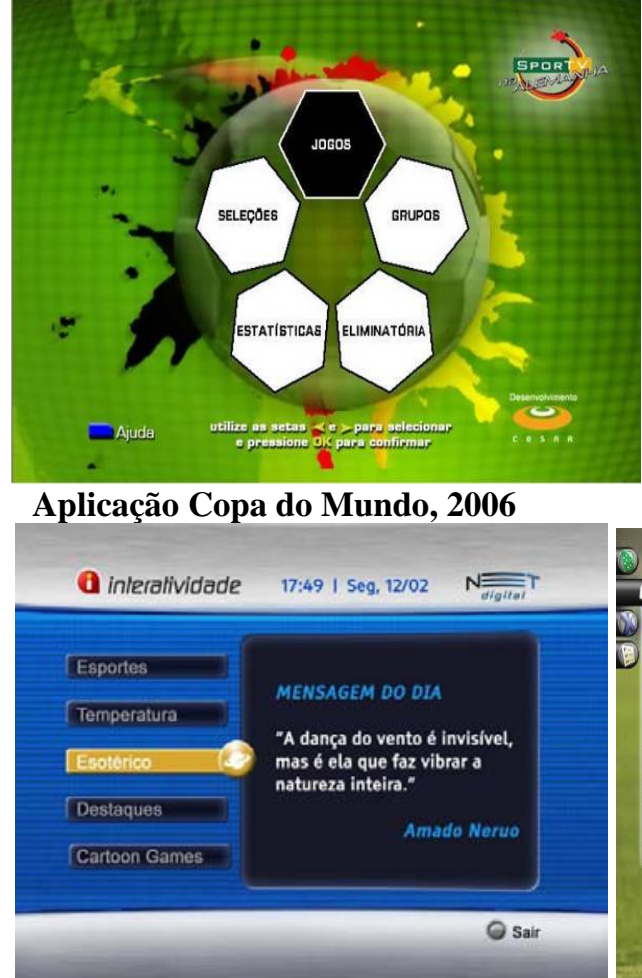

Aplicação Portal Net Digital

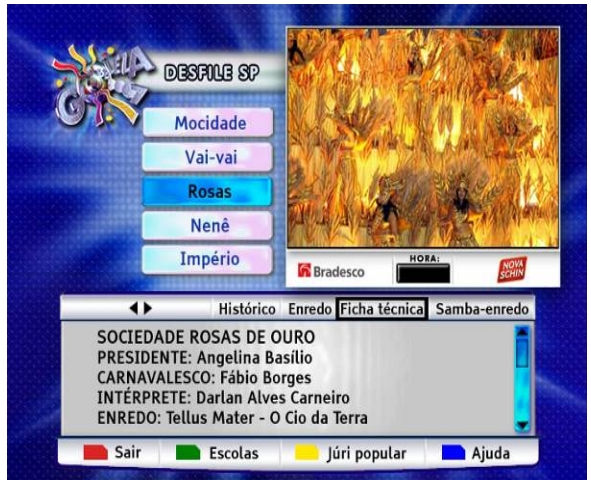

Aplicação Carnaval, 2007

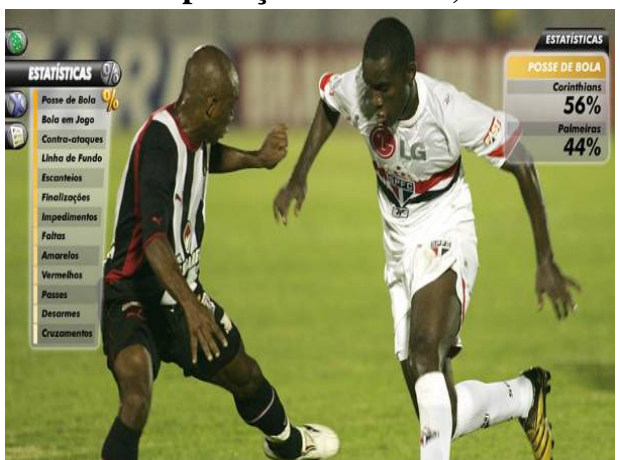

Aplicação Brasileirão, 2008

Figura 7. Aplicativos para TVDi desenvolvidos pelo C.E.S.A.R

É importante ressaltar que, pelo carente desenvolvimento de aplicações para a TVD brasileira, questões como usabilidade são muitas vezes baseadas em boas práticas da usabilidade na internert. A usabilidade das aplicações, tanto na internet como na TVD, é uma preocupação coerente uma vez que compromete o objetivo e valor informativo da interação da aplicação com o usuário. Serão apresentadas abaixo características da aplicação e as recomendações levadas em consideração no quesito usabilidade.

A aplicação Trânsito Legal é um simulador de um ambiente de TV digital em computador, onde a interação homem-máquina acontece totalmente através do uso do controle remoto. Conforme as recomendações de usabilidade há na tela de Ajuda informações de como usuário pode selecionar de forma correta a opção desejada através dos botões específicos para a execução de ações: vermelho, verde, amarelo, azul, i, OK e setas de navegação.

A aplicação foi concebida para atender ao requisito "simplicidade", em função dos recursos utilizados pelo usuário durante a interação, e quanto às limitações impostas pelo ambiente, como por exemplo, à distância e tamanho da tela. O limitar a quantidade de linhas de texto a 20 unidades, ajuda a evitar o uso de barras de rolagem de menus na tela. Não se utilizou linguagem técnica do tipo "Loading..." ou "Carregando...", e sim "Por favor, aguarde!”, por exemplo.

Durante a exibição da programação televisiva, será apresentado um símbolo de interatividade no canto superior direito da tela, avisando ao telespectador quanto a chegada de uma aplicação interativa que está disponível para ser executada, conforme apresentado na Figura 8. Considera-se como menos invasiva essa forma de chamar a atenção do telespectador, quando comparada a algumas aplicações que aparecem ao usuário sem que o mesmo requisite esse tipo de ação. 
A aplicação deverá ser implementada em um canal exclusivo de serviços de governo através de broadcast. Por meio de um portal, o telespectador poderá selecionar o tipo de curso desejado. O canal poderá compor, juntamente com a aplicação, um fluxo de áudio e vídeo, todavia ocupando somente parte da tela.
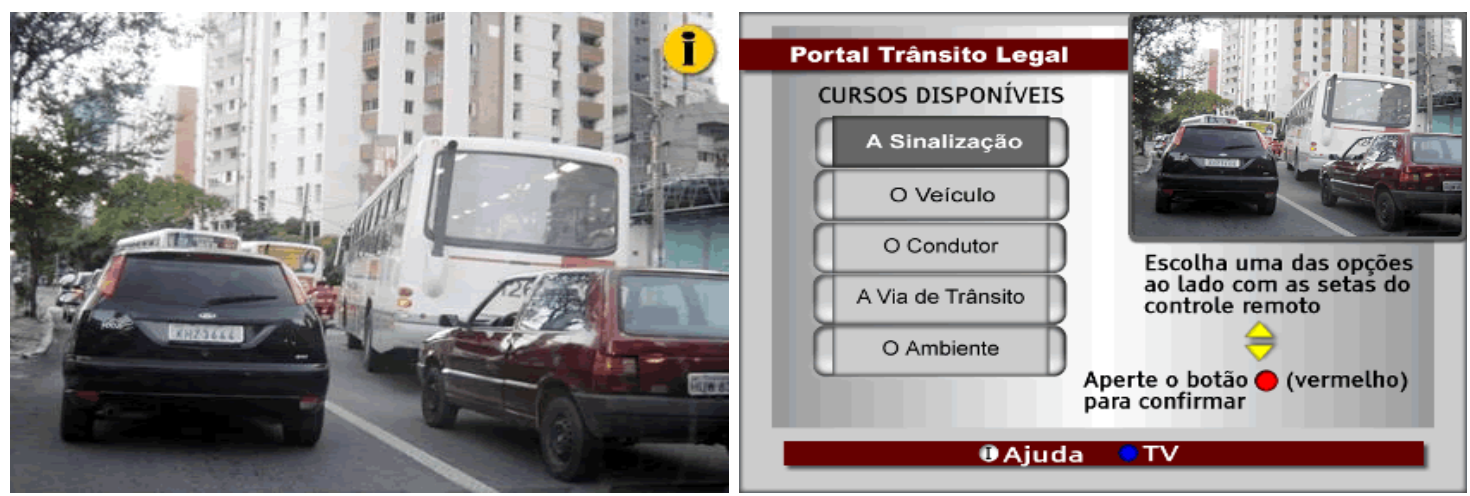

Figura 8. Indicativo de interatividade

As cores predominantes da aplicação são vermelho, amarelo e verde para criar uma sintonia temática com os sinais de trânsito. Para aplicações que utilizem o recurso de camadas, admite-se o uso de até três camadas: a camada de fundo, que pode conter uma imagem colorida ou uma cor de fundo, a camada sobreposta com um vídeo em tela cheia ou redimensionado, e uma última camada com todos os elementos gráficos. Nesse tipo de prática, deve-se ter um cuidado especial com a camada gráfica para que ela não venha a encobrir algum conteúdo ou que venha a gerar dificuldade para a visualização da narrativa.

Um menu principal apresentado em forma de semáforo e mantido ao lado esquerdo de todas as telas da aplicação. A seleção das opções: Sinais, Testes e Jogos, deverão ser feita através do controle remoto pressionando os botões vermelho, amarelo e verde, respectivamente. O segundo formato do menu é a uma espécie de sub-menu que disponibilizado em algumas telas da aplicação, tem o objetivo de flexibilizar a navegação vertical dentro do curso. Permite ao usuário avançar diretamente para um conteúdo localizado mais a frente do ponto em que ele se encontra (Figura 9).

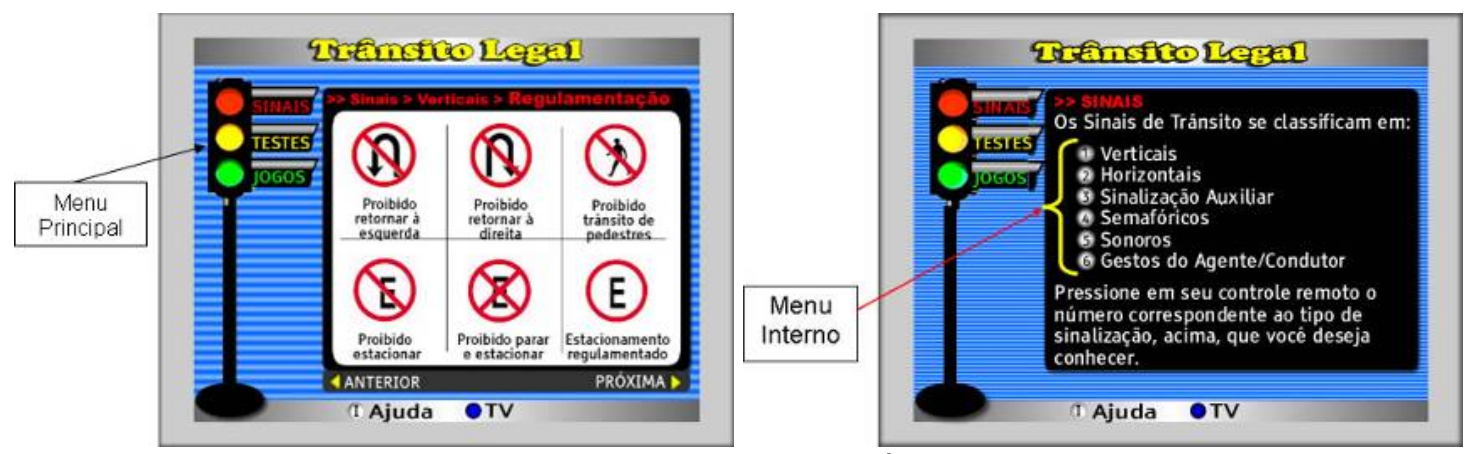

Figura 9. Menus do Trânsito Legal

Com relação às aplicações interativas que chegarão aos lares via broadcast, juntamente com elas também deverão estar contidos os recursos que levem o usuário a aprender por meio da diversão. Com certeza os jogos vêm ao encontro dessa expectativa, pois complementarão as aplicações com os atrativos necessários (bônus), que irão despertar no telespectador a vontade de realizar um determinado treinamento através da televisão. É 
recomendado não demorar mais do que 5 segundos para oferecer ao usuário feedback tão logo seja a sua ação.

\section{AVALIAÇÃO DA APLICAÇÃO TRÂNSITO LEGAL}

Com o objetivo de validar os resultados obtidos a partir da utilização do protótipo, foi realizada uma pesquisa que contemplou entrevistas, que são caracterizadas como métodos quantitativos e qualitativos (BAUER e GASKELL, 2002).

\subsection{Instrumentos para Coleta dos Dados}

Os instrumentos para a coleta dos dados foram questionários aplicados a 14 participantes conforme quadro 1. O primeiro questionário contém questões abertas e fechadas referentes à identificação do pessoal, e que serviu de base para o levantamento do perfil dos participantes. Foi entregue juntamente com este questionário, um guia com atividades que deveriam ser executadas durante a interação com o protótipo. Ao final da utilização do protótipo, foi entregue um segundo questionário contendo também questões abertas e fechadas para avaliar o grau de aceitação da aplicação.

\begin{tabular}{|c|l|}
\hline Atividade & \multicolumn{1}{|c|}{ Descrição } \\
\hline $1^{\text {a }}$. & $\begin{array}{l}\text { Utilize a aplicação da maneira que preferir com o objetivo de conhecer os } \\
\text { recursos oferecidos pela mesma (ajuda, navegação nas telas, uso do controle } \\
\text { remoto virtual, etc). Neste momento não será necessário seguir nenhuma } \\
\text { seqüência de procedimentos, servindo apenas para que você experimente a } \\
\text { aplicação. }\end{array}$ \\
\hline $2^{\text {a }}$. & $\begin{array}{l}\text { Após a execução da atividade anterior, você deverá acessar a área TESTES e } \\
\text { registrar o número de acertos. Caso o número de acerto for inferior a 10 (dez), } \\
\text { acesse a área SINAIS, estude um pouco a teoria e volte a realizar os TESTES, } \\
\text { e novamente, registre o número de acertos após o estudo. }\end{array}$ \\
\hline $3^{\text {a }}$. & $\begin{array}{l}\text { Acesse a área JOGOS, selecione a opção “Jogo da Memória”, divirta-se um } \\
\text { pouco e depois, encerre o jogo. }\end{array}$ \\
\hline $4^{\text {a }}$. & Encerre a aplicação \\
\hline
\end{tabular}

Quadro1 - Guia de Atividades Fonte: o autor

\subsection{Perfil dos Participantes}

Foi selecionado um grupo com características bastante heterogêneas pela razão de ser essa a realidade do tipo de público que utiliza a televisão diariamente, segundo Cybis, Betiol e Faust (2007, p. 286) “[...] o público-alvo das interfaces de TVDi é multivariado, abrangendo toda a população do país”.

- A metade das pessoas era do gênero feminino e a outra metade, masculino, com idades entre 18 e 73 anos;

- Cerca de 70\% dos participantes possuíam carteira de habilitação de motorista;

- A maioria tinha formação universitária;

- Todos possuem contato com a mídia TV; do total, oito pessoas responderam terem TV por assinatura; e só uma delas, utiliza recursos de interatividade além do uso do guia eletrônico de programação. 


\subsection{Análise do desempenho geral no Trânsito Legal}

Para análise do fator desempenho, foi solicitado aos participantes que registrassem a informação referente ao número de acertos obtidos através da realização de testes disponibilizados na aplicação. Essa tarefa foi realizada em dois momentos conforme orientação dada através de um guia de atividades, distribuído para cada participante durante a interação com o protótipo.

O teste de fixação disponibilizado continha 10 (dez) questões de múltipla escolha, todos com três alternativas, onde deveria ser selecionada uma única alternativa para um determinado texto ou imagem apresentada. Todas as perguntas foram elaboradas exclusivamente sobre o conteúdo teórico disponibilizado na aplicação, versando sobre o tema: sinalização de trânsito.

A cada nova tentativa em realizar o teste, as questões eram apresentadas embaralhadas randomicamente para que o respondente não decorasse simplesmente a posição da resposta. Ao final do teste, era apresentado um feedback ao participante com relação ao seu desempenho (Figura 10), utilizando metaforicamente as cores utilizadas nos semáforos (vermelho, amarelo e verde) para apresentar o nível de acertos obtidos e orientando o mesmo a retornar a seção teórica para reforçar os seus conhecimentos. No caso de até 05 (cinco) acertos era apresentado um feedback em "vermelho" indicando um desempenho abaixo do esperado; "amarelo” de 06 (seis) a 07 (sete) acertos; e "verde” entre 08 (oito) e (dez) acertos.
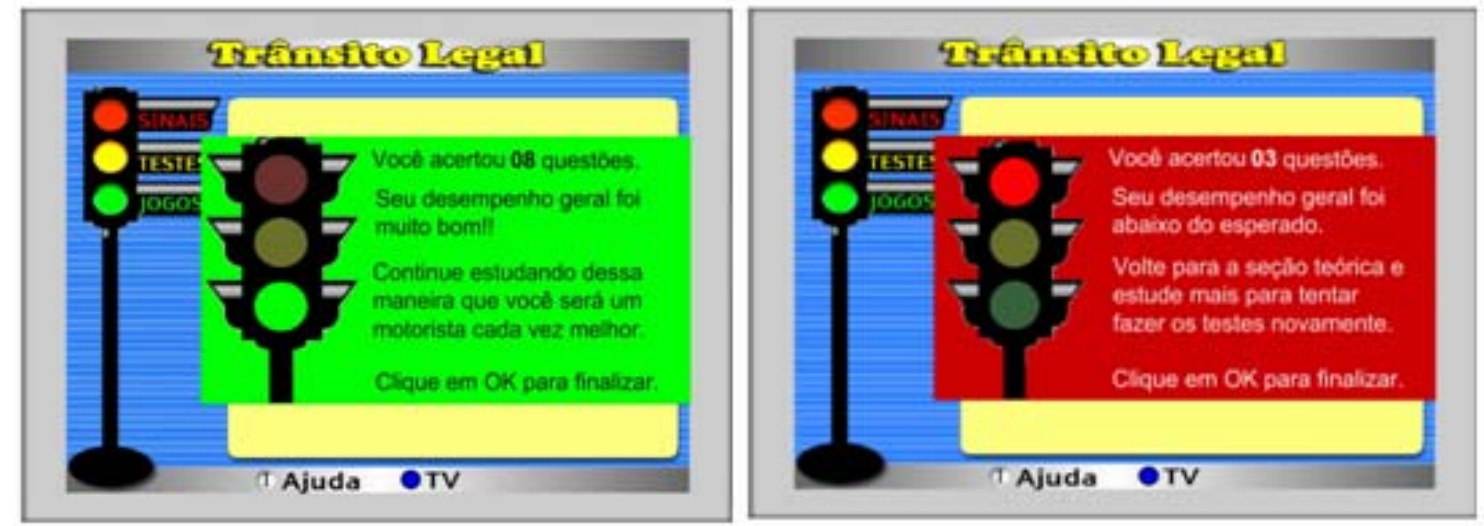

Figura 10. Tela contendo um feedback informando o desempenho nos testes

Verificou-se que quatro participantes, identificados pelos números 10, 11, 12 e 14, ainda não possuíam habilitação, tiveram um bom desempenho (8 acertos) já na primeira tentativa dos testes e melhoraram ainda mais na segunda tentativa, acertando em $100 \%$ as perguntas apresentadas. A média geral obtida pelos participantes na primeira tentativa foi de 7,29 elevadas para 9,64 na segunda tentativa (vide quadro 2).

\begin{tabular}{|c|c|c|c|}
\hline \multirow{2}{*}{ Participante } & \multicolumn{2}{|c|}{ No. de Acertos } & Melhoria \\
\cline { 2 - 3 } & $\begin{array}{c}\text { Primeira } \\
\text { Tentativa }\end{array}$ & $\begin{array}{c}\text { Segunda } \\
\text { Tentativa }\end{array}$ & $\begin{array}{c}\text { (+) } \\
\text { Ton }\end{array}$ \\
\hline 1 & 5 & 9 & $40 \%$ \\
\hline 2 & 6 & 9 & $30 \%$ \\
\hline 3 & 6 & 9 & $30 \%$ \\
\hline 4 & 6 & 9 & $30 \%$ \\
\hline 5 & 7 & 9 & $20 \%$ \\
\hline 6 & 7 & 10 & $30 \%$ \\
\hline
\end{tabular}




\begin{tabular}{|c|c|c|c|}
7 & 7 & 10 & $30 \%$ \\
\hline 8 & 8 & 10 & $20 \%$ \\
\hline 9 & 8 & 10 & $20 \%$ \\
\hline 10 & 8 & 10 & $20 \%$ \\
\hline 11 & 8 & 10 & $20 \%$ \\
\hline 12 & 8 & 10 & $20 \%$ \\
\hline 13 & 9 & 10 & $10 \%$ \\
\hline 14 & 9 & 10 & $10 \%$ \\
\hline
\end{tabular}

Quadro 2. Nível de desempenho na realização dos testes

No que se refere à avaliação da aplicação por parte dos participantes, pode-se concluir que os recursos (cursos, testes e material teórico) foram aceitos com perspectiva positiva. A avaliação atingia aspectos como os requisitos básicos referentes à interatividade local, atratividade da aplicação, simplicidade no uso e boa usabilidade e conseguiu uma média geral de $\mathbf{4 , 5 0}$ sendo a pontuação máxima 5,0.

No entanto, apesar das altas médias obtidas quanto às questões fechadas, algumas observações referentes à dificuldade na utilização da aplicação foram feitas pelos participantes nas questões abertas. Essas observações devem ser levadas em consideração caso uma nova versão do protótipo venha a ser futuramente implementada:

- Melhorar a visualização da identificação quanto ao caminho percorrido pelo usuário, principalmente quando houver subdivisões no assunto, com o objetivo de facilitar a localização (três ocorrências);

- Reduzir a quantidade de textos longos e utilizar mais imagens (duas ocorrências);

- Utilizar o controle remoto virtual (uma ocorrência).

\section{CONCLUSÃO}

A televisão digital interativa se apresenta como um recurso revolucionário e as expectativas a respeito dela são inúmeras. O que há princípio se imaginava da TVDi no Brasil, que ela seria apenas uma inovação tecnológica para "poucos”, perdeu força para o sentido que ela apresenta atualmente: a oportunidade de inclusão digital para milhões de brasileiros.

No Brasil, o serviço do Ensino e Educação a Distância, implementado inicialmente na TV analógica, é um dos serviços mais incentivados para ser reorganizado ou migradas para o novo modelo de transmissão de sinal televisivo.

Mesmo diante da indefinição do canal de interatividade da TVDi brasileira, empresas têm investido, com sucesso, tempo e dinheiro em aplicações com interatividade local focadas no Ensino e Educação a Distância.

Diante deste contexto, a pesquisa com a prototipação da aplicação Transito Legal apresentou que a TVDi é uma ferramenta aceita pela população, uma vez que aproximadamente $90 \%$ da mesma já tem em seus lares a TV aberta diminuindo assim a margem de uma não aceitação pelos brasileiros. A TVDi é um novo conceito, uma nova forma de inclusão Digital para e que agrega também uma nova forma de aprender com a TVDi, ou TV Digital interativa. 


\section{Referências Bibliográficas}

ADOBE (2009). Adobe Systems Incorporated. Adobe Flash. Disponível em: <http://www.adobe.com/products/flash>. Acesso em: março de 2009.

BATES, P. J. T-learning Study: A study into TV-based interactive learning to the home, Final Report, pjb Associates, UK, 2003. Disponível em: <http://www.pjb.co.uk/t-learning/contents.htm >. Acesso em: maio de 2008.

BAUER, M. W.; GASKELL, G. Pesquisa qualitativa com texto, imagem e som: um manual prático. 2 ed. Trad. Pedrinho A. Guareschi. - Petrópolis, RJ: Vozes, 2002. 516 p.

BRASIL. DENATRAN. Presidência da República. Decreto-Lei n. 9.503, de 29 de setembro de 1997. Código de trânsito brasileiro - CTB. Disponível em:

<http://www.denatran.gov.br/ctb.htm>. Acesso em: março de 2009.

CESAR. Centro de Estudos e Sistemas Avançados do Recife. Disponível em: <http://www.cesar.org.br>. Acesso em: março de 2009.

CYBIS, W.; BETIOL, A. H.; FAUST, R. Ergonomia e Usabilidade: conhecimentos, métodos e aplicações. São Paulo: Novatec, 2007. 344 p.

FÓRUM SBTVD. Fórum do Sistema Brasileiro de TV Digital. [On-line] 2008. Disponível em: <http://www.forumsbtvd.org.br/institucional.php>. Acesso em: junho 2008.

GARCÍA ARETO, Lorenzo. Educación a Distância Hoy. Madrid: UNED, 1995

JOKIPELTO, P. A. T-learning model for learning via digital TV. In: 16th EAEEIE conference, Lappeenranta, 2005, Filândia. Disponível em:

<http://www.it.lut.fi/eaeeie05/index.html>.Acesso em: julho de 2008.

MONTEIRO, B. de S. Amadeus-TV: Portal educacional na TV digital integrado a um sistema de gestão de aprendizado. Dissertação (Mestrado em Ciência da Computação) Centro de Informática, Universidade Federal de Pernambuco. Recife, 2009.

MONTEZ, C.; BECKER, V. TV Digital Interativa: conceitos, desafios e perspectivas para o Brasil. 2. ed. Florianópolis: Ed. da UFSC, 2005. 160 p.

MORAN, José Manuel. Novos Caminhos do Ensino a Distância. Informe CEAD, Rio de Janeiro, ano 1, n. ${ }^{\circ}$ 05, out./dez., 1994

MAROTO, Maria Lutgarda Mata. Educação a Distância: Aspectos Conceituais. Informe CEAD, Rio de Janeiro, ano 2, n. ${ }^{\circ}$ 08, jul./set., 1995

NUNES, I. B. Noções de educação à distância. Revista de Educação à Distância nrs. 4/5, Dez./93Abr/94. Brasília; Instituto Nacional de Educação à Distância, pp. 7-25. Disponível em: <http://www.rau-tu.unicamp.br/nou-rau/ead/document/?view=3>. Acesso em: maio de 2008.

SANTOS, A. C. O. dos. A digitalização da TV no Brasil: a sociedade civil organizada e a opinião pública a respeito do sistema brasileiro de TV digital - SBTVD. São Paulo: USP, 2006. Tese (Doutorado em Ciências da Comunicação) Escola de Comunicação e Artes, Universidade de São Paulo. São Paulo, 2006.

TAVARES, T.; SAIBEL, C. Concepção artística do programa interativo "A Turma da Árvore". 2005.

TEIXEIRA, L. Televisão digital: interação e usabilidade. Bauru: UNESP, 2008. Dissertação (Mestrado em Comunicação). Faculdade de Arquitetura, Artes e Comunicação, Universidade Estadual Paulista. São Paulo, 2008.

WAISMAN, T. Amazonas interativo: TV digital e educação interativa na Amazônia. In: 12. Congresso Internacional de Educação a Distância, 2005, Florianópolis, SC, 2005. Disponível em: <http://www.abed.org.br/congresso2005/por/pdf/160tcc5.pdf>. Acesso em: setembro de 2008. 